\title{
Uma proposta para a implementação da BNC-Formação 2019
}

\author{
Colaboração Educação Aberta ${ }^{1}$ \\ 27 de Setembro de 2021
}

\begin{abstract}
Resumo
Apresentamos uma interpretação para auxiliar na implementação da Resolução CNE/CP no 2 de 20 de dezembro de 2019, que define as Diretrizes Curriculares Nacionais para a Formação Inicial de Professores para a Educação Básica e institui a Base Nacional Comum para a Formação Inicial de Professores da Educação Básica (BNC-Formação).
\end{abstract}

palavras-chave: BNC-Formação, licenciaturas, currículo

A versão mais atualizada deste artigo está disponível em https://osf.io/67fx3/download

\section{Introdução}

1. Apresentamos neste white paper [1] um ensaio de como estruturar os currículos dos cursos de licenciatura nos três grupos formativos, contemplando as competências gerais (CG) docentes, competências específicas e suas habilidades (H): conhecimento (H.1), prática (H.2) e engajamento (H.3) profissionais.

${ }^{1}$ Todos os autores com suas afiliações aparecem no final deste artigo. 
2. Alguns itens a seguir foram extraídos na íntegra, enquanto outros tiveram sua redação adaptada, a partir da Resolução $\mathrm{CNE} / \mathrm{CP} \mathrm{n}^{\underline{0}} 2$ de 2019 [2].

3. O objetivo da metodologia empregada na composição deste documento é fornecer uma proposta para contribuir com a adequação curricular dos projetos pedagógicos dos cursos de licenciatura.

4. Nesta proposta, não estão contempladas as diretrizes para a educação infantil, ensino fundamental 1, educação a distância, os artigos 16, 17 e 18, os capítulos V, VI e VII, e a discussão sobre o processo avaliativo externo.

\section{Fundamentos e princípios para a organização curricular dos cursos de Licenciatura}

5. Formação inicial de professores para a educação básica em consonância com a Base Nacional Comum Curricular (BNCC).

6. Liberdade de aprender, ensinar, pesquisar e divulgar a cultura, o pensamento, a arte, o saber e o pluralismo de ideias e de concepções pedagógicas.

7. Compromisso com a qualidade da aprendizagem dos licenciandos, com equidade educacional, nas modalidades presencial e a distância.

8. Domínio de um conjunto de conhecimentos, habilidades, valores e atitudes: conteúdos pedagógicos e específicos de cada área do conhecimento, priorizando a integração teoria e prática.

9. Valorização das experiências anteriores dos licenciandos e respeito pelo seu direito de aprender, contribuindo para a redução das desigualdades sociais, regionais e locais. 
10. Construção de sólida formação básica (conhecimentos científicos e sociais) e vivência de experiências de aprendizagem exemplares, contemplando a indissociabilidade entre o ensino, pesquisa e extensão.

11. Valorização da profissão docente e da escola, reconhecendo-a como parceira imprescindível no planejamento, desenvolvimento e avaliação das atividades educacionais.

12. Fortalecimento da responsabilidade, do protagonismo e da autonomia dos licenciandos com seu próprio desenvolvimento profissional.

13. Valorização da prática como componente curricular (PCC) e estágios supervisionados, articulando formação inicial e continuada.

14. Aproveitamento dos tempos e espaços da prática nas áreas do conhecimento, nos componentes ou nos campos de experiência, para efetivar o compromisso com as metodologias inovadoras e os projetos interdisciplinares, flexibilização curricular, construção de itinerários formativos, projeto de vida dos estudantes, dentre outros.

15. Exploração de diferentes instrumentos de avaliação que considerem a matriz de competências desta resolução, bem como resultados de pesquisas científicas educacionais.

16. Adoção de uma perspectiva intercultural de valorização da história, da cultura e das artes nacionais, bem como das contribuições das etnias que constituem a nacionalidade brasileira.

\section{Estruturantes dos projetos pedagógicos de cur- sos (PPCs) das licenciaturas}

17. Todos os cursos em nível superior de licenciatura, destinados à Formação Inicial de Professores para a Educação Básica, serão organizados em três grupos, com carga horária total de, no mínimo, 3.200 horas. 


\section{GRUPO I}

18. 800 horas, para a base comum que compreende os conhecimentos científicos, educacionais e pedagógicos e fundamentam a educação básica e suas articulações com os sistemas, as escolas e as práticas educacionais.

19. Deve ter início no $1^{0}$ ano, a partir da integração das três dimensões das competências profissionais docentes - conhecimento, prática e engajamento profissionais.

20. As seguintes temáticas deverão ser contempladas no Grupo I, incluídas nas ementas ou conteúdos programáticos, registrados no PPC.

(I) Demonstrar conhecimento sobre currículos e seus marcos legais, incluindo (H.1.4.2, H.1.4.3, H.1.4.4, H.3.3.3, H.3.4.1):

(a) LDB 9394/96.

(b) Nos estabelecimentos de ensino fundamental e de ensino médio, públicos e privados, torna-se obrigatório o estudo da história e cultura afro-brasileira e indígena.

(c) Diretrizes Curriculares Nacionais (educação básica e específica de cada curso).

(d) Conceitos básicos da Educação Especial e inclusão das diferenças na escola.

(e) Base Nacional Comum Curricular (introdução, fundamentos e estrutura).

(f) Projeto Político-Pedagógico (PPP) da escola (Documento Curricular do Tocantins e/ou outros estados) e seus desdobramentos: gestão escolar, uso dos indicadores das avaliações externas, regimento escolar, planos de trabalho anual e compromisso com a comunidade escolar interna e externa, bem como instâncias de governança da educação (H.3.4.1). 
(II) Demonstrar conhecimento e prática profissional em didática e seus fundamentos, incluindo:

(a) Construir conhecimento contextualizado com a realidade da escola e dos estudantes, visando uma sociedade livre, justa, democrática e inclusiva (CG.1, H.3.3.3).

(b) Compreender a relevância do processo formativo e socioemocional dos estudantes, a fim de conhecer-se, apreciar-se e cuidar de sua saúde física e emocional, compreendendo-se na diversidade humana, reconhecendo suas emoções e as dos outros, com autocrítica e capacidade para lidar com elas, desenvolver o autoconhecimento e o autocuidado nos estudantes (CG.8).

(c) Demonstrar conhecimento de gestão e planejamento (campos de experiência, das áreas, dos componentes curriculares, das unidades temáticas e dos objetos de conhecimento) do trabalho pedagógico considerando diferentes ritmos, espaços, tempos e motivações dos estudantes, visando ao desenvolvimento das competências e habilidades previstas pela BNCC (H.2.1.1, H.2.1.2, H. 2.4.3).

(d) Planejar atividades avaliativas para subsidiar e garantir processos progressivos de aprendizagem e de recuperação contínua dos estudantes (H.2.3.2, H.2.4.3).

(e) Compreender o fracasso escolar não como destino dos mais vulneráveis, mas fato histórico que pode ser modificado, a partir do princípio de que todos são capazes de aprender (H.3.2.1, H.3.2.2).

$(f)$ Dar devolutiva em tempo hábil e apropriada, tornando visível para o estudante seu processo de aprendizagem e desenvolvimento, utilizando os resultados da avaliação para retroalimentar a prática pedagógica (H.2.3.3, H.2.3.4).

(g) Manter comunicação e interação com as famílias para estabelecer parcerias e colaboração com a escola, de modo que fa- 
voreça a aprendizagem dos estudantes e o seu pleno desenvolvimento (H.3.4.2).

(h) Fazer uso de sistemas de monitoramento, registro e acompanhamento das aprendizagens utilizando os recursos tecnológicos disponíveis (H.2.3.5).

(i) Explorar os fundamentos da pedagogia de projetos para aprendizagem colaborativa, exercitando a pesquisa, investigação, reflexão, análise crítica e criatividade (CG.2).

(j) Compreender o básico das tecnologias digitais de informação e comunicação (comunidades de aprendizagem virtuais, fenômenos digitais, pensamento computacional etc.) e suas implicações educacionais na busca por soluções tecnológicas para selecionar, organizar e planejar práticas pedagógicas desafiadoras, coerentes e significativas (CG.2, H.2.4.5, H.3.2.3, H.3.3.2).

(k) Aplicar metodologias e práticas de ensino ou didáticas específicas que possibilitem o domínio pedagógico dos conteúdos (H.2.1.3, H.2.4.1).

(l) Demonstrar conhecimento sobre as diferentes formas diagnóstica, formativa e somativa de avaliar a aprendizagem dos estudantes, utilizando o resultado das avaliações para: $(i)$ dar devolutivas que apoiem o estudante na construção de sua autonomia como aprendente; (ii) replanejar as práticas de ensino para assegurar que as dificuldades identificadas nas avaliações sejam solucionadas nas aulas (H.1.2.2, H.2.3.2).

$(m)$ Compreender a concepção e do papel da escola e do professor na sociedade por meio do exercício da empatia, do diálogo, da resolução de conflitos e da cooperação, fazendo-se respeitar e promovendo o respeito ao outro e aos direitos humanos, com acolhimento e valorização da diversidade de indivíduos e de grupos sociais, seus saberes, identidades, culturas e potencialidades, sem preconceitos de qualquer natureza, para promover ambiente colaborativo nos locais de aprendizagem (CG.9). 
(III) Exercitar o desenvolvimento acadêmico e profissional próprio, incluindo:

(a) Demonstrar conhecimento da cultura da escola (contexto econômico, político e sociocultural, territórios educativos e identidade dos estudantes), desenvolvimento de competências pessoais para aprimoramento da comunicação e interação interpessoais e intrapessoais, facilitando a mediação de conflitos escolares e desenvolvimento integral dos estudantes (H.1.2.3, H.1.3.1, H.3.1.2, H.3.2.3, H.3.4.3).

(b) Compreender os fundamentos históricos, sociológicos e filosóficos; das ideias e das práticas pedagógicas para melhor compreender as dimensões cognitivas, sociais, afetivas e físicas na vida de crianças, adolescentes, jovens e adultos em seu meio sociocultural (H.1.4.1).

(c) Demonstrar conhecimento sobre os processos pelos quais as pessoas aprendem, em cada etapa e faixa etária, devendo adotar as estratégias e os recursos pedagógicos (materiais didáticos, ferramentas e outros artefatos para a aula) alicerçados nas ciências da educação e suas evidências científicas atuais, advindas das diferentes áreas do conhecimento, que favoreçam o desenvolvimento dos saberes e eliminem as barreiras de acesso ao currículo (H.1.1.2, H.1.1.4, H.1.2.1, H.2.1.4, H.2.3.1).

(d) Construir um planejamento profissional utilizando diferentes recursos, baseado em autoavaliação, no qual se possa identificar os potenciais, os interesses, as necessidades, as estratégias, as metas para alcançar seus próprios objetivos e atingir sua realização como profissional da educação (H.3.1.1).

(e) Engajar-se em estudos e pesquisas de problemas da educação escolar, em todas as suas etapas e modalidades, e na busca de soluções que contribuam para melhorar a qualidade das aprendizagens dos estudantes, atendendo às necessidades de seu desen- 
volvimento integral (H.3.1.4).

(f) Engajar-se profissional e coletivamente na construção de conhecimentos a partir da prática da docência, bem como na concepção, aplicação e avaliação de estratégias para melhorar a dinâmica da sala de aula, o ensino e a aprendizagem de todos os estudantes (H.3.1.5).

(g) Construir um ambiente de aprendizagem que incentive os estudantes a solucionar problemas, tomar decisões, aprender durante toda a vida e colaborar para uma sociedade em constante mudança (H.3.2.5).

(h) Contribuir para o diálogo com outros atores da sociedade e articular parcerias intersetoriais que favoreçam a aprendizagem e o pleno desenvolvimento de todos (H.3.4.5).

\section{GRUPO II}

21. 1.600 horas, para a aprendizagem dos conteúdos específicos das áreas, componentes, unidades temáticas e objetos de conhecimento da BNCC, e para o domínio pedagógico desses conteúdos.

22. Deve efetivar-se do $2^{\mathrm{O}}$ ao $4^{\mathrm{O}}$ ano da graduação, segundo os três tipos de cursos, respectivamente destinados à formação de professores dos anos finais do Ensino Fundamental e do Ensino Médio.

23. As seguintes temáticas deverão ser contempladas no Grupo II, incluídas nas ementas ou conteúdos programáticos, registrados no PPC.

(I) Demonstrar conhecimento em língua portuguesa (comunicação oral e escrita; leitura, produção e utilização de diferentes gêneros textuais), considerando a norma padrão da língua (H.1.1.7).

(II) Demonstrar conhecimento matemático (produção, interpretação e uso das estatísticas e indicadores educacionais), a fim de conhecer, examinar e analisar os resultados de avaliações em larga 
escala, para criar estratégias de melhoria dos resultados educacionais da escola e da rede de ensino em que atua. (H.1.1.7, H.2.3.6).

(III) Demonstrar conhecimento digital (vivência, aprendizagem, utilização da linguagem digital, seleção de recursos pedagógicos digitais em situações de ensino e de aprendizagem, de forma crítica, significativa, reflexiva e ética para estimular uma atitude investigativa e a inclusão dos estruturantes da BNCC) (CG.5, H.1.3.4, H.2.1.5, H.2.4.5, H.3.2.7, H.3.3.2, H.3.4.3).

(IV) Demonstrar conhecimento pedagógico do conteúdo, explorando a criatividade e a inovação didática para ensinar os conteúdos específicos (uso de metodologias ativas de ensino e aprendizagem diversificadas: resolução de problemas, pedagogia de projetos, processos investigativos de aprendizagem, projetos de mediação e intervenção na realidade escolar etc.) (H.1.1.1, H.1.1.6, H.1.2.6, H.2.1.2, H.2.1.3, H.2.4.1).

(V) Aplicar estratégias de ensino diferenciadas que promovam a aprendizagem dos diferentes estudantes (deficiências, altas habilidades, estudantes de menor rendimento etc.), levando em conta seus diversos contextos culturais, socioeconômicos e linguísticos (H.1.2.5, H.2.1.2, H.2.1.3, H.2.4.1, H.2.4.2, H.2.4.3).

(VI) Articular teoria e prática, exercitadas na prática como componente curricular (PCC) e estágios supervisionados, considerando os componentes curriculares do PPC, a BNCC da educação básica e os fundamentos políticos: equidade, igualdade e compromisso do professor com o ensino e a aprendizagem (H.1.1.3, H.1.1.5, H.1.4.3, H.2.1.1, H.2.4.1, H.3.3.3).

(VII) Engajar-se com sua formação e seu desenvolvimento profissional, participação e comprometimento com a escola, com as relações 
interpessoais, sociais e emocionais (CG.8, H.3.1.2, H.3.1.5, H.3.4.1).

(VIII) Articular o item (23), subitens (I-VII), com as diretrizes curriculares nacionais específicas de cada curso.

24. Para o curso de formação de professores nos anos finais do Ensino Fundamental, e do Ensino Médio, as 1.600 horas, para aprofundar e desenvolver os saberes específicos, podem ser ofertadas, de acordo com a organização curricular, do seguinte modo: componentes curriculares, componentes interdisciplinares ou áreas de estudos, nos termos do respectivo Projeto Pedagógico do Curso (PPC).

\section{GRUPO III}

25. 800 horas para a prática pedagógica, assim distribuídas:

(a) 400 horas de estágio supervisionado, em ambiente de ensino e aprendizagem; e

(b) 400 horas (prática como componente curricular), ao longo do curso, entre os temas dos Grupos I e II.

26. Deve estar intrinsecamente articulada, desde o primeiro ano do curso, com os estudos e com a prática previstos nos componentes curriculares, priorizando algumas competências e habilidades:

(I) Valorizar e incentivar as diversas manifestações artísticas e culturais, tanto locais quanto mundiais, e a participação em práticas diversificadas da produção artístico-cultural para que o estudante possa ampliar seu repertório cultural (CG.3).

(II) Utilizar diferentes linguagens - verbal, corporal, visual, sonora e digital - para se expressar e fazer com que o estudante amplie seu modelo de expressão ao partilhar informações, experiências, ideias e sentimentos em diferentes contextos, produzindo sentidos que levem ao entendimento mútuo (CG.4). 
(III) Valorizar a formação permanente para o exercício profissional, buscar atualização na sua área e afins, apropriar-se de novos conhecimentos e experiências que lhe possibilitem aperfeiçoamento profissional e eficácia e fazer escolhas alinhadas ao exercício da cidadania, ao seu projeto de vida, com liberdade, autonomia, consciência crítica, responsabilidade e comprometimento com a escola (CG.6).

(IV) Desenvolver habilidades de níveis cognitivos superiores, argumentos com base em fatos, dados e informações científicas para formular, negociar e defender ideias, pontos de vista e decisões comuns, que respeitem e promovam os direitos humanos, a consciência socioambiental, o consumo responsável em âmbito local, regional e global, com posicionamento ético em relação ao cuidado de si mesmo, dos outros e do planeta (CG.7, H.1.2.4).

(V) Agir e incentivar, pessoal e coletivamente, com autonomia, responsabilidade, flexibilidade, resiliência, a abertura a diferentes opiniões e concepções pedagógicas, tomando decisões com base em princípios éticos, democráticos, inclusivos, sustentáveis e solidários, para que o ambiente de aprendizagem possa refletir esses valores (CG.10).

(VI) Compreender os objetos de conhecimento da BNCC que se articulem com os contextos socioculturais dos estudantes, para propiciar aprendizagens significativas e mobilizar o desenvolvimento das competências gerais da BNC-Formação (H.1.3.2, H.1.4.3, H.2.1.1, H.2.1.3).

(VII) Propor situações de aprendizagem desafiadoras e coerentes, de modo que se crie um ambiente de aprendizagem produtivo e confortável para os estudantes (H.2.1.6).

(VIII) Interagir com os estudantes de maneira efetiva e clara, adotando estratégias de comunicação verbal e não verbal que assegurem o entendimento por todos os estudantes (H.2.1.7).

(IX) Organizar o ensino e a aprendizagem de modo que se otimize a 
relação entre tempo, espaço e objetos do conhecimento, considerando as características dos estudantes e os contextos de atuação docente (H.2.2.1).

(X) Criar ambientes seguros e organizados que favoreçam o respeito, fortaleçam os laços de confiança e apoiem o desenvolvimento integral de todos os estudantes (H.2.2.2).

(XI) Construir um ambiente de aprendizagem produtivo, seguro e confortável para os estudantes, utilizando as estratégias adequadas para evitar comportamentos disruptivos (H.2.2.3).

(XII) Trabalhar de modo colaborativo com outras disciplinas, profissões e comunidades, local e globalmente (H.2.4.4).

(XIII) Fazer uso de intervenções pedagógicas pertinentes para corrigir os erros comuns apresentados pelos estudantes na área do conhecimento (H.2.4.6).

(XIV) Assumir a responsabilidade pelo seu autodesenvolvimento e pelo aprimoramento da sua prática, participando de atividades formativas, bem como desenvolver outras atividades consideradas relevantes em diferentes modalidades, presenciais ou com uso de recursos digitais (H.3.1.3).

(XV) Atentar nas diferentes formas de violência física e simbólica, bem como nas discriminações étnico-racial praticadas nas escolas e nos ambientes digitais, além de promover o uso ético, seguro e responsável das tecnologias digitais (H.3.2.4).

(XVI) Contribuir na construção e na avaliação do projeto pedagógico da escola, atentando na prioridade que deve ser dada à aprendizagem e ao pleno desenvolvimento do estudante (H.3.3.1).

(XVII) Apresentar postura e comportamento éticos que contribuam para as relações democráticas na escola (H.3.3.4).

(XVIII) Compartilhar responsabilidades e contribuir para a construção de um clima escolar favorável ao desempenho das atividades docente e discente (H.3.4.4). 


\section{Sobre o Estágio Supervisionado}

27. O processo instaurador da prática pedagógica deve ser efetivado mediante o prévio ajuste formal entre a instituição formadora e a instituição associada ou conveniada, com preferência para as escolas e as instituições públicas.

28. A prática pedagógica deve, obrigatoriamente, ser acompanhada por docente da instituição formadora e por um professor experiente da escola onde o estudante a realiza, com vistas à união entre a teoria e a prática e entre a instituição formadora e o campo de atuação.

\section{Sobre o Estágio Supervisionado e a Prática como Componente Curricular (PCC)}

29. A PCC deve estar presente em todo o percurso formativo do licenciando, com a participação de toda a equipe docente da instituição formadora, devendo ser desenvolvida em uma progressão que, partindo da familiarização inicial com a atividade docente, conduza, de modo harmônico e coerente, ao estágio supervisionado.

30. A PCC e o Estágio deverão ser engajados, incluindo a mobilização, a integração e a aplicação do que foi aprendido no curso, bem como deve estar voltada para resolver os problemas e as dificuldades vivenciadas nos anos anteriores de estudo e pesquisa.

31. As práticas devem ser registradas (portfólios, relatórios, memoriais reflexivos etc.) a fim de compilar evidências das aprendizagens do licenciando requeridas para a docência, tais como planejamento, avaliação e conhecimento do conteúdo.

32. As práticas mencionadas no parágrafo anterior consistem no planejamento de sequências didáticas, na aplicação de aulas, na aprendizagem dos educandos e nas devolutivas dadas pelo professor. 


\section{Do processo avaliativo interno}

33. As avaliações da aprendizagem e das competências devem ser contínuas e previstas como parte indissociável das atividades acadêmicas.

34. O processo avaliativo deve ser diversificado e adequado às etapas e às atividades do curso, distinguindo o desempenho em atividades teóricas, práticas, laboratoriais, de pesquisa e de extensão.

35. O processo avaliativo pode-se dar sob a forma de monografias, exercícios ou provas dissertativas, apresentação de seminários e trabalhos orais, relatórios, projetos e atividades práticas, entre outros, que demonstrem o aprendizado e estimulem a produção intelectual dos licenciandos, de forma individual ou em equipe.

36. Incluir a política de acompanhamento de egressos nos PPCs.

\section{Considerações Finais}

37. Esta é uma proposta preliminar, em desenvolvimento, que será aprimorada por meio de colaboração aberta.

\section{Ciência Aberta}

O arquivo latex para este artigo, juntamente com outros arquivos suplementares, estão disponíveis em [3]. Seja coautor(a) deste artigo, envie sua contribuição para mplobo@uft. edu.br.

\section{Como citar este artigo?}

https://doi.org/10.31219/osf.io/67fx3 


\section{Referências}

[1] Lobo, Matheus P. "Uma Revista Aberta." OSF Preprints, 19 July 2021. https://doi.org/10.31219/osf.io/fjb9a

[2] MEC. Ministério da Educação. Conselho Nacional de Educação. Conselho Pleno. Resolução CNE/CP n⿳ํㅡ 2, de dezembro de 2019. http://portal.mec.gov.br/docman/dezembro-2019-pdf/13595 1-rcp002-19/file

[3] Lobo, Matheus P. "Open Journal of Mathematics and Physics (OJMP)." OSF, 21 Apr. 2020.

https://doi.org/10.17605/osf .io/6hzyp

\section{Colaboração Educação Aberta}

Rosária Helena Ruiz Nakashima

(autora principal, rosaria@uft.edu.br) ${ }^{1}$

https://orcid.org/0000-0001-7798-6363

Matheus Pereira Lobo (autor principal, mplobo@uft.edu.br) $)^{1,2}$ https://orcid.org/0000-0003-4554-1372

${ }^{1}$ Universidade Federal do Norte do Tocantins (Brasil)

${ }^{2}$ Universidade Aberta (UAb, Portugal) 